\title{
La responsabilidad en el Código Civil y Comercial de la Nación. La violación al deber de no dañar
}

\section{POR GASTÓN L. MEDINA (*)}

\begin{abstract}
Sumario: I. Aproximación al tema.- II. La responsabilidad civil resarcitoria: los binomios "pago; imposibilidad-objetiva-definitiva" y "no-pago; imposibilidad-subjetiva-definitiva" - III. Los efectos de la obligación: "derecho al pago" y "deber de pago".- IV. La responsabilidad civil preventiva.- V. Conclusión.- VI. Bibliografía.
\end{abstract}

Resumen: las presentes reflexiones versan, desde un punto de vista peculiar, sobre uno de los temas más estudiados y discutidos a lo largo de la historia de las Ciencias Jurídicas, pero, sin embargo, sobre el que más oscuridad todavía hoy persiste. Nos referimos al concepto, índole y eficacia de la responsabilidad civil, a la luz del derogado Código de Vélez y del nuevo Código Civil y Comercial de la Nación. Así, desde la perspectiva puesta en la responsabilidad civil, desde su doble función (preventiva y resarcitoria) intentaremos demostrar las razones por las que, actualmente, se constituye como única causa fuente de la obligación de reparar, ya sea el riesgo de daño, ya sea el daño causado, mediante su compensación (indemnización), su morigeración (no agravamiento), o su cese (no continuación), según el caso.

Palabras claves: responsabilidad civil - obligación - causa - efectos

\section{The liability in the Civil and Commercial Code of the Nation: The violation of the duty not to harm}

Abstract: The present reflections deal, from a peculiar point of view, on one of the most studied and discussed topics throughout the history of Legal Sciences, but nevertheless, on which more darkness still persists today. We refer to the concept, nature and effectiveness of civil liability, in light of the repealed Vélez Code and the

(*) Abogado especializado en Derecho Social, Universidad Nacional de La Plata. Diplomado en Derecho Romano, Universidad Abierta Interamericana. Doctorado en Ciencias Jurídicas, Universidad Nacional de La Plata. Prof. ordinario Derecho Romano, Facultad de Ciencias Jurídicas y Sociales, Universidad Nacional de La Plata; Facultad de Ciencias Económicas y Jurídicas, Universidad Nacional de La Pampa y Facultad de Derecho, Universidad de Buenos Aires. Miembro fundador y Secretario del Instituto de Historia y Derecho Romano, Colegio de Abogados de La Plata. 
new Civil and Commercial Code of the Nation. Thus, from the perspective placed on civil liability, from its dual function (preventive and compensatory), we will try to demonstrate the reasons why, at present, it is constituted as the only source cause of the obligation to repair, whether the risk of damage, either the damage caused, through its compensation (compensation), its death (not aggravation), or its cessation (not continued), as the case may be.

Keywords: civil liability - obligation - cause - effects

\section{Aproximación al tema}

Desde antaño, la doctrina ha sostenido que los hechos jurídicos(1) de "pago" y "no-pago", son efectos propios (generales y accidentales, respectivamente) de toda relación obligacional. Con este sentido, hallábamos al artículo 505 - in fine - del Código Velezano, que decía: “(...) el cumplimiento exacto de la obligación le confiere el derecho de obtener la liberación (...)". El artículo 724 - in fine- del Código Civil y Comercial de la Nación (CCiv. y Com.), que dice: “(...) y, ante el incumplimiento, a obtener forzadamente la satisfacción de dicho interés". En igual sentido y alcance, el artículo 731 del CCiv. y Com., expresa: "(...) el cumplimiento exacto de la obligación confiere al deudor (...)"; y el artículo 777 CCiv. y Com. que reza: “(...) el incumplimiento imputable de la prestación le da derecho al acreedor (...)", etc.

Permítasenos, aunque resulte prematuro, anticipar nuestra opinión sobre el error que encierra dicha concepción. Así, veremos cómo esta interpretación tradicional nos introduce en un mar de confusiones en el que naufragar será inevitable, salvo que nos aferremos al salvavidas del uso aquilatado del pensamiento y del lenguaje.

En rigor de verdad, debemos pensar a ambos supuestos ("pago" y "no-pago") como configurativos de hechos jurídicos autónomos(2), frente a la obligación,

(1) Cabe señalar que, la consideración de "pago" como un simple "hecho jurídico" se adecua mejor al método seguido en el presente trabajo, en el que se desestima a la "voluntad", en sí misma, como causa fuente autónoma, al tiempo que se enaltece, la fuerza eficiente de la ley que rige la virtualidad de todo hecho o acto. Por su puesto, de ordinario, el hecho jurídico de pago, será voluntario y lícito, es decir, será "acto jurídico". No obstante ello, en otros casos (por pocos no menores), será un mero hecho jurídico, como ocurre en el pago de obligaciones de "no hacer", o en algunos casos de pago por incapaz. Asimismo, nos ha parecido adecuado, para el encuadre conjunto del pago y del no-pago, en una misma categoría. En este sentido se han expresado autores como Marcadé, Puig Peña y Orgaz, para quienes la gran variedad de situaciones en que puede consistir el pago dificulta su absoluto encuadre en una especie única.

(2) Que son hechos independientes y distintos. 
pues tienen una causa eficiente propia, distinta a la relación obligacional en sí (con la cual, sólo conservarán una relación de referencialidad) y, más aún, diversa de la causa-fuente (contrato; declaración unilateral; ley) que le haya dado origen.

Causa propia que, pensamos hallarla, ya en la "voluntad del sujeto" que paga, ya en la "voluntad objetiva de la ley", cuando el deudor omite cumplir culposamente o, dado el caso, cuando alguna circunstancia (hecho) sobreviniente, ajena o no al deudor (imputable o no a éste), imposibilita el pago ("imposibilidad subjetiva definitiva" e "imposibilidad objetiva definitiva (casus)".

Hay tres razones centrales - se anticipa- por las que el "incumplimiento-culpable-definitivo" (no-pago) queda equiparado a la "imposibilidad-subjetiva-definitiva" de pago. La primera, refiere a que ambos casos comparten la misma causa fuente: la voluntad imperativa y objetiva de la ley. La segunda, que los efectos son los mismos: la extinción de la obligación originaria por la creación de otra nueva, destinada a reemplazarla (conf. artículo 933 del CCiv. y Com.), cuyo objeto "modificado", convierte a la obligación "en la de pagar una indemnización" (conf. 955 CCiv. y Com.). Henos aquí, ante un claro supuesto de novación por disposición de la ley (conf. artículo 941 CCiv. y Com.). La tercera y última, que en los dos casos la prestación originaria ha sido irrealizada de modo definitivo.

Es muy importante que el incumplimiento o la imposibilidad sean definitivos. De lo contrario, nos hallaremos bajo los efectos de la obligación originaria que clama por ser satisfecha, espontánea o forzadamente (según el caso), mediante el cumplimiento in-natura o específico de la prestación. De modo que, el mero retardo de cumplimiento (mora), aunque sea imputable (culpa-dolo), no configura el hecho idóneo de la responsabilidad civil que da lugar a la obligación de reparar.

Dicho esto, cabe recordar, que la voluntad siempre configura una causa fuente de obligaciones ficcionaria o aparencial, ya que la fuente jurígena por excelencia es, en rigor, la ley (3). Tal es así, que, aunque las partes pretendan evitar, al tiempo

(3) Esta afirmación merece una explicación, ya que en modo alguno representa la opinión mayoritaria. En ninguno de los textos antiguos, ni en el célebre comentario de Ulpiano a Labeón de Digesto 50.16.19, ni en la brillante Institutas (III) de Gayo, se reconoce a la voluntas como fuente eficaz de derecho. Por el contrario, el término ni es empleado. Sólo se observa el vocablo consensus que, en rigor, no alude a la "autonomía de la voluntad" (dispénseme el anacronismo lingüístico) como fuente de obligaciones sino a la reciprocidad prestacional, es decir, a lo que los griegos llamaban sinalagma (bilateralidad funcional). De modo que, la idea de voluntad como causa fuente corresponde a una de las tantas "ficciones" o "abstracciones" jurídicas de la "modernidad" que, proclamada por el naturalismo racionalista de la Pandestística alemana (Grocio, Pufendorf, etc.), recibida más tarde por la Escuela francesa (Domat, Pothier, etc.), influyó notablemente en la elaboración de los códigos modernos durante los S. XVI y XIX. Por lo que, puede afirmarse, que para la tradición jurídica histó- 
del nacimiento, los efectos propios de la obligación(4), ello les será indisponible bajo pena de nulidad por razón de orden público. Ya que, en rigor, ni siquiera su voluntad es cuestionada por la ley a la hora de juzgar la validez o invalidez del pago efectuado. Por lo que, aconsejamos interpretar, que la voluntad en relación con el pago y al no-pago, debe comprenderse como un "prius psicológico" sin el cual no habría en sí acto, sino mero hecho, con prescindencia de los efectos jurídicos que nacen y terminan en la ley.

Así, separando al "pago" y al "no-pago", de la obligación; independizando ambos hechos de los efectos de aquella, e identificando su causa y sus consecuencias propias, intentaremos superar la eterna aporía (5) en relación con la supuesta "doble" naturaleza de la responsabilidad civil: "causa" y "efecto" simultáneo, de obligaciones.

Sin perder de vista esta finalidad, intentaremos demostrar de qué modo y por qué razones, ambos hechos (pago; no-pago) tienen sus efectos propios, que se diferencian perfectamente de los efectos normales (generales) y anormales (accidentales), atribuidos por la doctrina autoral y jurisprudencial tradicionalista a las obligaciones.

Resulta importante, antes de continuar, dejar en claro que este trabajo es un intento de crítica en sentido estricto de la palabra, es decir, como "crisis" o "cambio-superador", ante la interpretación tradicional, en torno, principalmente, de los efectos anormales o accidentales, mal atribuidos a la obligación. Puesto que, como será debidamente elucidado, dichos efectos son consecuencias propias del "nopago", comprendido como todo "incumplimiento- antijurídico-imputable" (6) al deber de no dañar (7), que constituye la responsabilidad civil en su función resarcitoria, en su condición de fuente exclusiva de la obligación de reparar, tal como ha sido regulado por el nuevo Código Civil y Comercial de la Nación.

Sentado lo dicho, nos explicamos.

rica, la voluntad adquiere su virtualidad jurídica del reconocimiento de la ley, sobre lo que no esté prohibido, sobre lo permitido.

(4) Sobre cuáles son los efectos propios a toda obligación, se dará detallado y oportuno tratamiento en acápite especial. Anticipamos, que nos apartaremos de la tradicional clasificación de los efectos en "necesarios o generales" y "accidentales", entre otras cuestiones que abordaremos.

(5) Contradicción lógica insuperable.

(6) A lo debe sumarse el carácter de "definitivo", si la responsabilidad civil es un no-pago.

(7) En la sección IV del presente trabajo abordaremos el concepto de responsabilidad civil preventiva, entendida como el incumplimiento antijurídico imputable al deber de prevenir todo daño, o evitar su agravamiento o continuidad. 


\section{La responsabilidad civil resarcitoria: los binomios "pago; imposibilidad- objetiva-definitiva" y "no-pago; imposibilidad-subjetiva-definitiva"}

Siguiendo la línea de pensamiento hasta aquí expuesta, es correcto afirmar que los efectos propios del hecho jurídico de pago (cumplimiento) son la extinción de la obligación principal con todos sus accesorios y la consiguiente liberación espontánea del deudor.

Por su parte, el artículo 865 del CCiv. y Com. define al pago como el cumplimiento de la prestación que configura el objeto de la obligación.

Cabe ahora preguntarnos sobre los efectos propios del "no-pago" (incumplimiento). Pensamos que el efecto propio del hecho jurídico de "no-pago", también lo constituye la extinción de la obligación principal y sus accesorios, por causa de ese hecho autónomo de eficacia novatoria que modifica - objetivamente(8)a la obligación originaria, que se extingue, convirtiéndose(9) en una nueva (en "otra"), destinada a reemplazarla, y cuyo contenido será el derecho al pago de una indemnización sustitutiva de la prestación primigenia, esto es, la obligación de reparar(10). He aquí, la razón de ser del "no-pago", como un supuesto de causa autónoma de la obligación de reparar que, de la mano de otros hechos ilícitos (11), configura esa nueva y única causa-fuente de la obligación de resarcir que, el nuevo CCiv. y Com., ha dado en llamar responsabilidad civil.

En este sentido, el artículo 1716 dice "Deber de reparar: La violación del deber de no dañar, o el incumplimiento de una obligación, da lugar a la reparación del daño causado, conforme con las disposiciones de este código".

De modo que, la responsabilidad civil en su función resarcitoria(12), refiere a todo hecho ilícito que viole la prohibición general de no dañar (alterum non laedere), es decir, que ocasione un daño antijurídico (conf. artículo 1717 del CCiv.

(8) A nivel de su prestación o contenido patrimonial.

(9) El artículo 955 del CCiv. y Com., que regula sobre el casus -o "imposibilidad objetiva-definitiva" - y la "imposibilidad subjetiva-definitiva", es claro en este alcance. Dicha norma dice: "artículo 955. Definición: (...) Si la imposibilidad sobreviene debido a causas imputables al deudor, la obligación modifica su objeto y se convierte en la de pagar una indemnización de los daños causados" (destacado nuestro). A su vez, el artículo 933 del CCiv. y Com. dice: "Definición. La novación es la extinción de una obligación por la creación de otra nueva, destinada a reemplazarla” (el destacado es de mi autoría).

(10) No debe confundirse con la responsabilidad civil, que es su causa-fuente.

(11) Tales como la "imposibilidad subjetiva-definitiva" (artículo 955 CCiv. y Com.) y todo hecho que implique la violación al "deber de no dañar" (artículo 724 CCiv y Com.): los "delitos y cuasidelitos” del Código de Vélez, siguiendo su tradición romanista.

(12) A su turno, explicaremos el concepto de responsabilidad civil en su función preventiva. 
y Com.), ya mediante el "no-pago" imputable de una obligación, ya mediante la comisión de cualquier otro hecho antijurídico dañoso (conf. artículos 1717 y 1737 del CCiv. y Com.).

De la norma transcripta surge claramente que, ambos supuestos (comisión de un hecho dañoso y "no-pago"), son equiparados por la nueva ley, ya desde su índole (ambos son antijurídicos), ya desde sus efectos propios (ambos dan origen a la obligación de reparar). De modo que la responsabilidad civil, en su función resarcitoria, configura la exclusiva causa fuente de la obligación de reparar y, en este sentido, ha servido a la unificación de las, otrora, categorías (regímenes, ámbitos normativos, etc.) de "responsabilidad contractual" y "extracontractual", originadas en la escuela francesa (13). Hete aquí, la "unicidad de fundamento" (no de regímenes, ya que subsisten diferencias) proclamada por la Comisión Reformadora que, en efecto, ha operado en el nuevo Código, a través del llamado "fenómeno de antijuricidad".

Es tiempo de retomar, ahora, el discurso sobre los efectos del "pago" y del "nopago". Si bien es cierto que ambos supuestos conservan en común el mismo efecto jurídico, a saber, la extinción de la obligación originaria y sus accesorios, son muchas más sus diferencias. Así, mientras que en el "pago", al ejercerse un derecho, campea la licitud (14), el "no-pago" transita el plano de la ilicitud, configurando según la tradicional clasificación Justinianea-, ya un "cuasidelito", ya un "delito", civil o penal, según el caso (15). Asimismo, mientras el pago configura, de ordinario, un acto jurídico emanado de la virtualidad atribuida por la ley a la "voluntad" del deudor(16), con una directa intención extintiva, por el contrario, el "no-pago",

(13) Categorías desechadas por Vélez por motivo de la confusión implicada (en) y derivada (de) ellas. Su origen se remonta a la escuela francesa del siglo XVII, sobre cuyos tratados jurídicos se elaboró, más de un siglo después, el Código Civil Francés (Código Napoleón), primer código civil moderno. Así, de la lectura de las obras de juristas como Domat, Dumoulin y Pothier, se observa la notoria preeminencia dada a las obligaciones nacidas de contratos y, a éstos, como fuente de aquellas; lo cual se explica a la luz de la relevancia otorgada al principio de autonomía de la voluntad, hija de la "voluntad de poder".

(14) El artículo 731 habla de un "derecho a obtener la liberación" o, lo que es igual, un "derecho de pago".

(15) Nos parece justo, por razones históricas y didácticas, la referencia "parcial" a la clasificación de obligaciones tetra-partita (ex contractus; ex cuasi-contractus; ex delictus; ex cuasi-delictus) que empleaba el Corpus Justinianeo (S. VI) sobre las enseñanzas del gran pedagogo Gayo (S. II), más allá de su no empleo en el nuevo Código.

(16) Ya veremos que, el llamado "pago por tercero", no configura en sentido técnico un "pago", sino por contrario, un caso de novación "compuesta" o "mixta" (subjetiva-objetiva) de origen legal (artículo 941 CCiv. y Com.). 
cuando es definitivo, halla su eficacia en la objetiva voluntad de la ley, a través del instituto de novación objetiva legal(17).

Y ello, claro está, siempre y cuando estemos ante un incumplimiento definitivo-absoluto (18), puesto que la referida novación, se perfecciona en el ámbito del proceso(19), en el que se persigue la ejecución forzosa de la obligación, específicamente, en el marco de la litis-contestatio (20). A dichas diferencias se suma otra: así, mientras que a consecuencia directa de la extinción por el "pago" sucede la liberación del deudor, no corre la misma suerte la extinción operada por el "nopago" mediante la novación legal, ya que el deudor continuará sujeto a su statusdebitori hasta la satisfacción total de la nueva obligación de reparar nacida a la luz del propio incumplimiento, es decir, de la responsabilidad civil.

Sin perjuicio de ello, en modo alguno corresponderá afirmar que la obligación originaria se ha "perpetuado" en otra prestación, porque esa no es la eficacia o efecto del instituto novatorio, que es siempre la extinción. Esa obligación, ya es pasado. La vigencia de intereses moratorios y/o punitorios pactados; del valor afectivo o artístico de la cosa objeto de la prestación; de la naturaleza intuito personae; de derechos de garantía (prenda, hipoteca); no deben pensarse como efectos de la "vieja obligación", "vigentes o perpetuados" en el contenido prestacional de la "nueva obligación" de reparar, sino que su eventual consideración ulterior, halla fundamento en el principio de reparación plena (artículo 1743, 1746 y concs. del CCiv. y Com.), según el cual la reparación debe procurar el restablecimiento del estado de indemnidad anterior al daño; lo que el derecho romano llamó status quo anque. Así, ante la responsabilidad civil, es decir, frente el incumplimientoantijurídico-imputable al deber de no dañar (artículo 19 Constitución Nacional -C.N.-) (21), se activa la garantía de indemnidad que exige, imperativamente,

(17) La extinción opera en la novación, mediante la transformación de la obligación originaria en otra nueva, cuyo objeto es la reparación, y que reemplazará a la anterior (933 CCiv. y Com.).

(18) En contraposición al transitorio-relativo.

(19) Salvo los casos de acuerdo conciliatorio extrajudicial, y/o transaccional judicial, en los que la novación es convencional.

(20) La litis-contestatio trae aparejado la llamada "traba de la litis" que, en rigor, refiere a sus efectos procesales típicos sobre los elementos del proceso. El primero de estos, es la novación objetiva que produce sobre la prestación originaria que, extinta, es reemplazada por la nueva de pagar una indemnización sustitutiva. Segundo, la fijación (permanente e inmutable) de las partes, el objeto (novado), los hechos y la acción del proceso. Antes de la "traba", todavía queda la posibilidad del cumplimiento in natura o específico de la prestación primigenia, aunque sea, tardíamente y bajo los efectos de la mora, lo cual ya no es posible, acontecida la novación.

(21) Gran parte de doctrina constitucionalista, ha visto en la norma del art. 19 de la Carta Magna, la consagración de la "garantía de indemnidad", como límite infranqueable a la "garantía de libertad individual" que expresamente reconoce. Así, a las acciones privadas de los hombres, la misma 
"volver al estado anterior al daño" como realización plena de esa garantía. De modo que, su continuidad, será sólo en relación con las reglas que rigen la determinación del "quantum" o "extensión del daño resarcible", con fundamento en el principio de reparación integral referido.

Ahora bien, llegado el punto, cabe referirnos a la llamada teoría de la relación jurídica compleja.

Creemos que dicha tesis, de origen alemán y conocida por los sintagmas "débito" y "responsabilidad", es incorrecta, siendo causa de múltiple confusión, toda vez que incluye entre los efectos de la obligación a un efecto propio del hecho de su incumplimiento, la obligación de reparar, que ha sido confundida por gran parte de la doctrina con la responsabilidad civil(22).

Por esta razón, Jorge J. Llambías (1973) soslayó siempre a la teoría germana, no incluyendo en la definición de obligación el tramo de la responsabilidad(23). Es el propio maestro quien en su tratado expresa que si bien es posible la obligación sin "responsabilidad", cuyo ejemplo es la especie obligación natural, por el contrario, resulta imposible concebir una obligación sin "débito" (deber de conducta prestacional), lo que deja en claro que es éste y no aquel el elemento esencial y estructural de toda obligación.

Cuando el artículo 724 del CCiv. y Com.(24) — desoyendo el consejo de Vélez de abstención de definiciones legales-define a la obligación desde el vértice del acreedor y, punto seguido, refiere al supuesto de incumplimiento, no está completando ni agregando nada a la primera parte, sino que se refiriere a la responsabilidad civil resarcitoria y/o preventiva, y sus efectos, como hecho jurídico autónomo. Lo contrario es inadmisible, porque no es lícito presumir tamaña redundancia del legislador, ni tal grado de asistematicidad.

Ello, viene a reforzar aún más lo dicho sobre la autonomía del "pago; imposibilidad-objetiva- definitiva" y "no-pago; imposibilidad-subjetiva-definitiva", frente a

norma antepone un límite insoslayable (amén del orden y la moral, públicas), a saber, que no “(ni) perjudiquen a un tercero".

(22) Cabe aclarar que, para parte importante de la doctrina nacional entre las que se hayan juristas que han formado parte del proyecto de reforma, la responsabilidad civil se confunde con la propia "obligación de reparar" que, en rigor, es su efecto.

(23) En igual sentido la definición de las Institutas del Corpus Justinianeo, que siguen los comentaristas y la doctrina autoral nacional.

(24) El artículo 724 dice: "definición: La obligación es una relación jurídica en virtud de la cual el acreedor tiene el derecho a exigir del deudor una prestación destinada a satisfacer un interés lícito, o no reprobado por el derecho y, ante el incumplimiento, a obtener forzadamente la satisfacción de dicho interés". 
la obligación y sus varias causas, pero por sobre todo, su independencia y distinción frente a los efectos de la obligación.

Ha llegado el momento de echarle otra mirada al artículo 955 del Código Civil y Comercial.

Como ya anticipamos, la norma regula sobre dos supuestos de extinción de la obligación por causas sobrevinientes, a saber: 1) imposibilidad-objetiva-definitiva, de cumplimiento; 2) imposibilidad-subjetiva (25)-definitiva, de cumplimiento. La diferencia principal entre ambos, consiste en la ausencia de culpabilidad (imputabilidad) en el primero y la presencia de ella en el segundo. Así, mientras que en el primer supuesto (caso fortuito; fuerza mayor), el incumplimiento definitivo de la prestación no tiene nexo causal con la conducta del deudor, sino que es consecuencia de una causa ajena y objetiva, en el segundo, la conducta del deudor es la causa adecuada del incumplimiento definitivo. De esta distinción, surgen otras. Así, mientras que la imposibilidad-objetiva-definitiva extingue la obligación principal con sus accesorios y libera al deudor, "como si" fuera un pago (26), por contrario, la imposibilidad- subjetiva-definitiva extingue la obligación por novación legal, modificando a la obligación desde su objeto y convirtiéndola en otra (nueva) que la reemplaza, cuyo objeto será la obligación de reparar mediante el pago de una indemnización sustitutiva, como si se tratara de un incumplimiento culposo, es decir, un no pago imputable al deudor.

Esta nueva obligación (de reparar) tiene, por derecho correlativo del acreedor, la facultad de exigir el pago de una indemnización, que es un efecto propio de la responsabilidad civil en su función resarcitoria.

Así surgía del artículo 505 del derogado Código derogado y, actualmente, así surge de los artículos 724 - in fine-, 730 inc. c) y 777 inc. c) del CCiv. y Com. Ambos efectos son tratados dentro de la sección $1^{\text {a }}$, referida a "disposiciones comunes" a toda obligación y en la sección $2^{\text {a }}$, referida a las "obligaciones de hacer o no hacer". Estas normas, en efecto, regulan, como si fueran efectos de la obligación, consecuencias jurídicas propias del binomio "no-pago; imposibilidad-subjetivadefinitiva" que, conforme el sentido y alcance reseñados desde el inicio de estas reflexiones, configura hechos jurídicos autónomos, de eficacia extintiva, más allá del reemplazo de una obligación por otra nueva fruto de la novación legal.

Podemos representarlo en el siguiente esquema:

Binomio 1: "pago; imposibilidad-objetiva-definitiva".

(25) Ya que es imputable a la culpa del sujeto (factor subjetivo de atribución).

(26) He aquí, la razón del binomio "pago - imposibilidad objetiva definitiva (casus)". 
Binomio 2: "no-pago; imposibilidad-subjetiva-definitiva".

Cada binomio está integrado por actos y/o hechos jurídicos autónomos respecto de la obligación, sus causas y sus efectos.

En el primer binomio, la equiparación se realiza a partir del común efecto derivado de ambos, a saber, la extinción de la obligación principal con todos sus accesorios y la consecuente liberación del deudor. Se dice, es este sentido, que el caso fortuito se asimila al pago.

En el segundo, asimismo, la conexión encuentra razón por medio de sus consecuencias jurídicas: la extinción por novación legal de la obligación principal con sus accesorios, pero sin la consiguiente liberación de deudor. Puede afirmarse, así, que cuando la imposibilidad sobreviniente, resulta imputable al deudor, la equiparación al no-pago culposo resulta inevitable.

Cabe reiterar que, ambos binomios, mantienen una relación referencial con la obligación; jamás de pertenencia. Así, el pago, si bien guardan una relación estrecha con la obligación que se cancela, por razones lógicas y de sentido común, sin embargo, sería incorrecta la atribución de sus efectos a la obligación. La propia ley civil es clara en esta cuestión. Los efectos del pago se hallaban implícitos en el inciso 1 del derogado artículo 505, y en el inciso a) de los actuales artículos 730 y 777 del CCiv. y Com. En rigor, debió haber sido el artículo 731 del CCiv. y Com. el que regulara sobre el pago, como deber de conducta a cargo del deudor, que define su status debitori frente al acreedor. Sin embargo, dicha norma se refiere al "derecho de liberación del deudor" como "efecto propio de la obligación en relación con el deudor", reiterando el yerro lógico de hacer nacer, de la obligación, consecuencias jurídicas propias del hecho autónomo extintivo de pago.

De modo que, luce incorrecto seguir afirmando que estamos, en estos casos, ante consecuencias jurídicas de la obligación, cualquiera sea su causa (contrato; convención; responsabilidad civil; ley; etc.).

En suma, ni el "pago" es efecto de la obligación (sí, "derecho al pago" y "deber de pago"), ni la extinción que éste provoca se debe, en efecto, a la obligación en sí misma, sino al pago. A su vez, el "no-pago" (artículos 724 - in fine-; 730 inciso c), y 777 inciso c), CCiv. y Com.) y la "imposibilidad-subjetiva-definitiva" (artículo 955 del CCiv. y Com.), que se le equipara formando el binomio 2), son efectos de la obligación.

De modo que, cuando el artículo 777 del CCiv. y Com. dice: "el incumplimiento imputable de la prestación le da derecho al acreedor a: (...) c) reclamar los daños y perjuicios", no hace otra cosa que, incorrectamente, atribuir efectos propios de 
la responsabilidad civil a la obligación lo cual resulta un absurdo. Nos explicamos: primero, porque ello implicaría atribuir una eficacia extintiva a la obligación, lo cual resulta imposible. Segundo: cuando el artículo dice, "el incumplimiento imputable de la prestación", quiere decir, "ante la responsabilidad civil", ya que en eso ella consiste. Tercero, el derecho al pago de una indemnización del acreedor que reclama por daños y perjuicios, no halla su causa en la obligación, sino en su incumplimiento, es decir, en la responsabilidad civil como fuente de la obligación de reparar (artículo 1716 del CCiv. y Com.). Por último, una razón lógica incontrastable: la imposibilidad lógica, de considerar a hechos contingentes e hipotéticos como si fueran ciertos y reales. Estos son: el "pago", el "no-pago" y, con más razón, todo caso de imposibilidad sobreviniente idónea para extinguir por "casus" o por "novación legal", según estemos ante una "imposibilidad-objetiva-definitiva", o ante otra "subjetiva", respectivamente. Así, mientras la "imposibilidad-objetivadefinitiva" opera por "casus" (27), que se asimila al pago, dando lugar a la liberación del deudor; mientras que la imposibilidad-subjetiva-definitiva", opera por novación legal, identificándose con el "no-pago" imputable, dando lugar a la extinción por transformación de su objeto (indemnización) sin la consiguiente liberación del deudor, por las razones ya expuestas.

Estos eventos, cuyo acontecer aún es potencia, no pueden tenerse por acontecidos prima facie, es decir, al tiempo del nacimiento de la obligación originaria; al igual que no puede tenerse por cierto aquello que todavía no ha sucedido, aquello que es contingente.

¿Cuáles serán, entonces, los efectos propios e inherentes a toda obligación?

\section{Los efectos de la obligación: "derecho al pago" y "deber de pago"}

Toda obligación (relación jurídica intersubjetiva) coloca al acreedor en una posición jurídica (status creditori), cuyo rol jurídico correspondiente, es la capacidad de derecho de ser satisfecho en un interés lícito o no reprobado por el Derecho (artículo 724 CCiv. y Com.). Éste configura el efecto propio, directo o inmediato, de toda obligación en relación con el acreedor. Ahora bien, puede que ocurra el pago; empero, puede acontecer el no-pago. En este caso, se abren dos caminos. Por un lado, constituido en mora el deudor, los efectos de esta operan durante la transitoriedad del incumplimiento y, llegado el caso, más allá, hasta la sentencia y la satisfacción forzosa del nuevo crédito indemnizatorio.

En este sentido, podemos afirmar, sin temor a equívocos, que todo acreedor tiene "derecho al pago", al igual que un propietario tiene "derecho a la posesión"

(27) Nominativo indicativo del "caso fortuito" y su equiparable "fuerza mayor". 
pero, en modo alguno, podemos inferir que ese derecho a ser satisfecho pueda asimilarse al hecho jurídico de pago mismo, como tampoco podemos identificar el derecho a la posesión con el hecho jurídico de la posesión misma. Y esto es tan así, que hasta podemos encontrarnos con un propietario que ha perdido la posesión sobre la cosa de su pertenencia, quedando tutelado sólo mediante la acción petitoria o rei-vindicatio, que ejercerá contra el tercero poseedor, del mismo modo que un acreedor que no ha sido satisfecho en su interés ejercerá la acción civil contra el deudor remiso. Podremos afirmar, en este caso, que el propietario tiene derecho a la posesión, pero ésta, como hecho autónomo, le ha sido perdida.

Por su parte, la misma obligación colocará al deudor en la situación jurídica (status debitori - capacidad de derecho) de sujeción a un deber jurídico de conducta frente al acreedor, siendo este "deber de pago" su efecto directo e inmediato en relación con el deudor. Por las razones expuestas, en modo alguno dicho deber puede ser confundido con el hecho de pago mismo, ni con sus efectos.

Llegado el punto, a mayor abundamiento, cabe recordar que el inciso 2) del antiguo artículo 505 del Código Velezano; como el actual inciso b) del artículo $730 \mathrm{o}$ el 777 inciso b) del CCiv. y Com. prevén entre los efectos propios de la obligación al "pago por un tercero" a cargo del deudor, no obstante tratarse (el tercero) de quien ni siquiera tiene un "deber de pago" frente al acreedor y, sin embargo, "paga", válida y eficazmente, produciéndose los efectos propios y normales de todo pago, no de la obligación por cierto inexistente, entre el acreedor y el tercero pagador. En rigor de verdad, para mejor decir, no "paga" en sentido estricto, puesto que ello le resultaría jurídicamente imposible, atento su falta de capacidad jurídica para el acto. El status debitori pertenece exclusivamente al deudor, o a quien éste o la ley lo ceda, y ello así, conforme lo que en doctrina se conoce como efecto relativo de contratos y de las obligaciones. Por lo que, en el llamado "pago por tercero", lo que ocurre en realidad, es una novación "compuesta" o "mixta" de carácter legal. No hay cesión, sino subrogación (novación subjetiva), no subsiste la obligación anterior en cabeza de otro sujeto, sino extinción de esta (mediante novación objetiva) y su reemplazo por la creación de otra nueva (artículo 933 ss. y cc. CCiv. y Com.), a cargo del tercero.

Este supuesto "pago" sin "débito", sólo es posible merced a la autonomía jurídica del pago frente a la relación jurídica obligacional, porque no hay obligación - stricto sensu - sin débito, así, como no hay debido sin causa.

No cabe duda que dicho tercero es extraño al status debitori, por lo que no puede considerárselo, constreñido a ningún deber de conducta frente al acreedor (que configura la esencia de la obligación), sin embargo, acontecido el "pago", éste produce sus efectos propios (extinción de la obligación originaria con todos sus accesorios), con la salvedad de que, a semejanza de lo ocurrido en el binomio 
"no pago; imposibilidad-subjetiva-definitiva", en que la liberación del deudor no se produce, a pesar de la extinción por novación objetiva. En este caso, tampoco acontecerá la liberación, no obstante la extinción de la obligación originaria por virtud de la novación mixta (subjetiva-objetiva), producida ope-legis (28).

De modo que, cuando el Código de Vélez y el actual Código (artículo 731) prevén, entre los efectos de las obligaciones, el derecho del deudor de exigir su liberación y repeler las acciones del acreedor, no hacen más que mal atribuir a la obligación efectos propios y normales del pago. El mismo yerro se observa al otro extremo de la relación obligacional, el acreedor, tal como fue explicitado.

Ambos status (debitori - creditori), son las partes o centros de interés, que configuran los contrapuntos de una misma relación obligacional. Representan el binomio de correlación indisoluble, existente entre "deber - derecho". Así, al derecho del acreedor a la satisfacción de su interés (derecho al pago), corresponde el deber jurídico a cargo del deudor de satisfacerlo (deber de pago o "débito"). Pero, hete aquí -error lógico mediante-, la doctrina tradicional ha considerado parte integrante del binomio al derecho del deudor de exigir su liberación y repulsa de acción, mediante el pago (29), y ello, no obstante la claridad de la norma del artículo 731, que expresamente atribuye esos derechos al hecho de "pago" (no a la obligación), en perfecta consonancia, con lo dispuesto por el artículo 880 del CCiv. y Com. de la Nación, cuando dice "La norma citada reza: efectos del pago por el deudor. El pago realizado por el deudor que satisface el interés del acreedor, extingue el crédito y lo libera".

De modo que, no quedan dudas, los derechos de liberación y repulsa de acción resultan del pago, no de la obligación cancelada. Ello, sin perjuicio de la poco feliz expresión inicial del artículo 731 “(...) efectos con relación al deudor (...)", en referencia al contenido de las obligaciones. Porque, así como el pago no puede jamás formar parte del contenido prestacional u objeto de una obligación, mucho menos podrán integrarla sus efectos. Puesto que si "pago" es el cumplimiento del "objeto" de la obligación, no puede ser, a su vez, el objeto mismo.

(28) A diferencia del caso comparativo, en estos supuestos de pago por tercero, la novación será siempre "compuesta" o "mixta", es decir, subjetiva y objetiva, ya que cambia la persona del acreedor (subjetiva) y la prestación originaria por un monto dinerario (objetiva).

(29) Llamado "derecho de pago", previsto como efecto de las obligaciones respecto del deudor en el artículo 731 del CCiv. y Com., que reza: "Efectos con relación al deudor: El cumplimiento exacto de la obligación confiere al deudor el derecho a obtener la liberación y el de rechazar las acciones del acreedor". 
De igual manera, el derecho a la reparación(30), en cabeza del acreedor insatisfecho o del damnificado por algún otro ilícito dañoso, nace de la responsabilidad civil, teniendo como contrapartida al correlativo deber de reparar, en cabeza del "responsable".

Se ha dicho, respecto del término "responsable", que configura un vocablo vulgar no aconsejable en el derecho (31), en cuyo ámbito resultaría pertinente hablar de "deudor". En efecto, ello es correcto ante la obligación, pero frente a la responsabilidad civil, la cuestión cambia y el uso surge adecuado, ya que al tratarse aquella de una causa fuente autónoma, el deudor remiso (o el autor de otro ilícito) adquiere la nominación de "responsable" que, en sentido técnico-legal, refiere siempre a quien tiene a su cargo la obligación de reparar, nacida de su incumplimiento (nopago), o de la "imposibilidad-subjetiva-definitiva" de cumplimiento (32).

Retomemos lo dicho sobre los status jurídicos. Con ellos, se nos presenta la obligación en todo su esplendor, como instrumento de paz social entre los hombres, y no como causa de conflicto, puesto que toda obligación conlleva un derecho a ser satisfecho, más que un señorío de exigir o hacerse pagar (33). Del mismo modo, desde la parte pasiva, implica siempre un deber de conducta del deudor, más que un derecho a obtener su liberación, aunque la poco-feliz definición del artículo 724 del CCiv. y Com. no diga nada al respecto.

Las obligaciones nacen para satisfacer una necesidad humana lícita, lo que contribuye a la paz; no para generar conflictos mediante el incumplimiento total, parcial o defectuoso, que dará origen a la conducta forzosa, ya del acreedor, ya del deudor, según quien incurra en mora (34).

Como si lo dicho no bastara, para rever al menos, el estado actual de la doctrina que atribuye a la obligación los efectos jurídicos del "incumplimiento-antijurídico-imputable" esto es, la responsabilidad civil, cabe agregar lo siguiente.

(30) El crédito indemnizatorio.

(31) En esta línea, Martínez (2017, pp. 36-41).

(32) Así, mientras el autor de cualquier ilícito violatorio al deber de no dañar, nace siendo "responsable", por su parte, el deudor de una obligación, nace deudor y se convierte, mediante el no pago, en responsable.

(33) El propio artículo 243 del CCiv. y Com. llama "poder de agresión" al "derecho al pago", lo cual no parece coherente con una perspectiva que enaltece al Derecho, como instrumento de paz entre los hombres y como límite insoslayable al poder político, económico y/o religioso, cuando éste entre en colisión con el valor inviolable de la dignidad de la persona humana.

(34) En este punto, resulta llamativa la orfandad del artículo 724 del CCiv. y Com. respecto de la mora e incumplimiento definitivo del acreedor. 
El "no-pago", al carecer de juricidad(35), inhabilita la mentada atribución, ya que de hacerse, se estaría ante un "derecho a incumplir", lo cual es jurídicamente imposible, pues la regla de no dañar (alterum non laedere), impide esa comprensión. Lo que está prohibido no produce más efectos que su nulidad, salvo que la ley le atribuya otro, no siendo el caso. De modo que el "no-pago" nunca podrá forma parte del contenido prestacional de la obligación, porque no existe tal prerrogativa dentro de la capacidad jurídica del deudor (status debitori), quien siempre tiene a su cargo la obligación de cumplir con la prestación; ni dentro de la capacidad del acreedor (status creditori), quien siempre tiene derecho a ser satisfecho en su interés lícito.

La lógica del precepto alterum non laedere así lo establece: no hay derecho a dañar; no hay deber de soportar daño alguno más allá del implicado en el normal desarrollo de la vida social.

Por todo lo expuesto, podemos afirmar, que la responsabilidad civil constituye la violación al deber de no dañar, ya sea mediante el incumplimiento-antijurídicoimputable de una obligación preexistente (no-pago), ya sea mediante cualquier otro modo de incumplimiento-antijurídico-imputable (acto dañoso antijurídico), dando lugar, en cualquiera de los casos, a la obligación de reparar, es decir, de compensar económicamente dicho daño, mediante el pago de una suma dineraria (indemnización sustitutiva).

\section{La responsabilidad civil preventiva}

Sentado lo dicho hasta ahora sobre el sentido (significado) y el alcance (eficacia) de la responsabilidad civil, parecería haberse logrado cierto nivel de certeza y claridad, desde luego, en el marco epistemológico de la presente postura. Ahora bien, ¿qué decir, frente a la función preventiva que, el nuevo Código atribuye a la responsabilidad civil?

El artículo 1708 del CCiv. y Com. establece dos funciones de la responsabilidad civil: la prevención del daño y su reparación.

De una primera lectura de la norma y, olvidando todo lo dicho en los párrafos precedentes, podríamos creer que la responsabilidad consiste en una fuente lícita de obligaciones y, aunque parezca natural dicho pensar, sería un razonamiento incorrecto. Basta leer los términos "prevención" y "reparación" para caer en la confusión, puesto que ambos refieren a grandes valores sociales y jurídicos que la responsabilidad, como instituto, intenta realizar.

(35) Este es el sentido del artículo 1716 del CCiv. y Com. 
Pero ello no modifica la índole antijurídica de esta causa fuente de la obligación, que siempre supondrá un hecho u acto, dañoso, antijurídico (conf. artículos 1716, 1717, 1737, y cctes.) e imputable, no obstante sus innegables bondades: prevención-reparación.

Aclarada esta cuestión, corresponderá dilucidar otra.

La responsabilidad civil es una sola. Ella responde, siempre, a un mismo concepto, del cual se ha dado cuenta en los párrafos precedentes. Sus dos funciones, en modo alguno importan, dos clases o especies del género responsabilidad, sino un desdoblamiento a nivel funcional de ésta.

El artículo 1716 refiere expresamente a que la responsabilidad civil da lugar al "deber" (36) de reparar, pero no precisa el contenido de dicha reparación. Por qué razón debemos comprender, que sólo se refiere a la reparación por medio de una suma de dinero equivalente (indemnización sustitutiva) ¿Acaso quien restablece un estado de riesgo o daño potencia creado, no repara dicho estado, previniendo? $S I$ ¿Acaso quien evita el agravamiento o, por caso, la continuación del daño ya producido, no repara también? SI ¿Acaso la norma citada, expresamente, refiere a la indemnización como única forma de reparación? NO.

Sin embargo, este desdoblamiento funcional, implica cierta diferenciación sin el grado de la especie. La responsabilidad civil preventiva, precede al daño que, por contrario, configura siempre un presupuesto de la responsabilidad resarcitoria. Sin embargo, en ambas, está presente la función reparadora. Mientras que en la preventiva, el daño es potencial, en la resarcitoria es, necesariamente, actual. Sin embargo, el daño (ya potencial; ya actual) es cierto en ambas. En este sentido, el artículo 1737 brinda una definición jurídica muy amplia de daño, como toda lesión a un interés humano lícito (derecho subjetivo expreso), o no reprobado por el derecho (no reconocido expresamente por la ley, pero tampoco prohibido). De modo que, conforme la línea trazada por dicha norma, no debemos reducir la denotación jurídica del término daño, al daño actual con exclusión del potencial (riesgo). Siempre y cuando, dicho daño (actual-potencial) cumpla las exigencias de razonabilidad y certeza, impuestos por la naturaleza de las cosas (37). Asimismo, es exigencia legal impuesta por el artículo 1712 CCiv. y Com. la acreditación de un interés razonable en la prevención del daño. No siendo necesario se trate de un interés lícito expresamente reconocido (derecho subjetivo), mientras no se trate de un interés reprobado (artículo 1737).

(36) Extraña expresión de la norma, solo aceptable, desde la óptica de la obligación como deber jurídico particular.

(37) Léase, orden natural de las cosas, curso ordinario de la experiencia. 
A su turno, la norma del artículo 1710 dispone otra diferencia entre ambas funciones. Así, mientras la responsabilidad resarcitoria requiere, para su configuración, la concurrencia de cuatro presupuestos (daño, antijuricidad, imputación y causalidad), ninguno de ellos es requisito de la función preventiva. Ello se explica, a la luz del carácter de medida cautelar de origen legal, que reviste la función preventiva de la responsabilidad civil. Así, el artículo 1712, expresamente consagra una "acción preventiva" que, no es otra cosa, que una acción autosatisfactoria de origen legal que, no sólo está exenta de los presupuestos ordinarios de la responsabilidad civil, sino, asimismo, de los requisitos procesales para la admisión ( $f u$ mus iuris; periculum in mora, cautio) de toda medida cautelar.

Sin embargo, tanto el artículo 1708, como el 1710 (38) y siguientes(39) — que regulan específicamente la función preventiva- brindan un singular y novedoso aporte a la hermenéutica de la responsabilidad civil en el nuevo Cuerpo, ya que ahora, la responsabilidad también se activa mediante la violación potencial a la regla que prohíbe dañar, mediante la creación de "riesgo", es decir, al generarse la situación razonable de que un daño acontezca (artículo 1710). Las normas se refieren también a la obligación de evitar todo daño antijurídico de un tercero como, asimismo, la continuidad o agravamiento del daño ya producido por aquel (artículo 1711).

De modo que, cuando la norma del artículo 1737, define al daño antijurídico o daño resarcible como aquel provocado sin causa legal de justificación (1717) contra un derecho subjetivo, o un interés no reprobado por el derecho, debemos interpretarla en armonía con la norma del artículo 1711, que amplía los supuestos de responsabilidad civil al acto u omisión antijurídicos, que generen un riesgo razonable de daño contra algún interés humano.

Las consecuencias de la nueva normativa son las siguientes: 1) la responsabilidad civil, en su función preventiva, acontece ante el riesgo razonable de que un daño suceda; 2) haciendo nacer la obligación de evitarlo o impedirlo, no agravarlo

(38) El artículo 1710 dice: “deber de prevención del daño. Toda persona tiene el deber, en cuanto de ella dependa, de: a) evitar causar un daño no justificado; b) adoptar, de buena fe y conforme a las circunstancias, las medidas razonables para evitar que se produzca un daño, o disminuir su magnitud; si tales medidas evitan o disminuyen la magnitud de un daño del cual un tercero sería responsable, tiene derecho a que éste le reembolse el valor de los gastos en que incurrió, conforme a las reglas del enriquecimiento sin causa; c) no agravar el daño si ya se produjo".

(39) Artículo 1711: Acción preventiva. La acción preventiva procede cuando una acción u omisión antijurídica hace previsible la producción de un daño, su continuación o agravamiento. No es exigible la concurrencia de ningún factor de atribución. Artículo 1712: Legitimación: están legitimados para reclamar quienes acrediten un interés razonable en la prevención del daño. 
ni continuarlo, ya se trate de actos propios, o de terceros por los que se deba o no responder.

De modo que, aun en este plano, en este rol preventivo, la responsabilidad civil sigue siendo causa fuente de obligación, ya no de resarcir económicamente, sino de reparar las condiciones de seguridad e indemnidad alteradas, a fin de evitar que todo daño acontezca, conforme la índole del contrato o de las circunstancias particulares del caso, cuando no mediare uno; atendiendo siempre el curso natural y ordinario de la experiencia.

\section{Conclusión}

Como conclusión a las elucidaciones precedentes podemos aseverar, que conforme el nuevo Código Civil y Comercial de la Nación, la responsabilidad civil refiere a la violación al deber de no dañar (40) (artículo 1716), a través de cualquier hecho o acto que configure un incumplimiento-antijurídico-imputable (no-pago; imposibilidad-subjetiva-definitiva; cualquier otro hecho o acto dañoso resarcible) que dé lugar al nacimiento de la obligación de reparar, ya el riesgo de daño, su agravamiento o su continuación (función preventiva: 1708, 1710, 1711, 1712, 1716), ya el daño, real y actual, mediante su compensación dineraria o indemnización (función resarcitoria 1708, 1716, 1730, 1743, 1746, ss. y cc.).

Po último, un reconocimiento especial. El mérito mayor que pude atribuirse a la comisión reformadora ha sido la elaboración de conceptos amplios de antijuricidad (1717) y de daño (1737), íntimamente vinculados (41), que ha posibilitado el desdoblamiento funcional de un mismo instituto, la responsabilidad civil, en un "rol preventivo" y en otro "resarcitorio". Dos modos distintos de atención a una misma necesidad: la reparación integral del status quo anque, esto es, del estado anterior al riesgo, o al daño.

Creemos, que no corresponde soslayar a la obligación bajo la sombra de la responsabilidad civil, pero tampoco corresponde vaciar de contenido a ésta en función de la teoría general de la obligación. Ningún extremo es conveniente.

El faro debe de iluminar a las distintas soluciones desde un cristal de comprensión jurídica sistemático y armonioso, desde donde el complemento reemplace a la exclusión, la sistematicidad a la contradicción, que debiera de ser sólo

(40) Corpus: Digesto. Ulpiano. 1.1.10 - Institutas. 1.1.3.

(41) El pasaje - también de Domicio Ulpiano- del Corpus: Digesto. Ulpiano. 9.2.5.1, expresamente dice "sed quod non iure factum est, hoc est contra ius", esto es, que todo daño se presume hecho contra el ius. 
aparente en un sistema jurídico, cuando es hijo del estudio profundo y de la madura reflexión.

\section{Bibliografía}

Llambías, J. J.; Raffo Benegas, P. y Sassot, R. A. (1977). Compendio de Derecho Civil: obligaciones. Buenos Aires: Perrot.

Llambías, J. J. (1973). Tratado de Derecho Civil: obligaciones. Tomos I, II, III. Buenos Aires: Perrot.

Martínez, J. P. (2016). La responsabilidad civil en el nuevo Código Civil y Comercial de la Nación: sus dilemas. La Plata: Librería Editora Platense.

Martínez, J. P. (2016). El Derecho de las Obligaciones en el nuevo Código. La Plata: Secretaría de Extensión. Facultad de Ciencias Jurídicas y Sociales. UNLP.

Medina, G. L. (2018). La discriminación objetiva: bases para una teoría general de los Derechos Humanos. Revista Anales, № 48. Facultad de Ciencias Jurídicas y Sociales. Universidad Nacional de La Plata. Buenos Aires: La Ley.

Negri, H. (2015). Reflexiones sobre la derogación del Código Civil (claudicación de la cultura). Revista Anales, número extraordinario. Facultad de Ciencias Jurídicas y Sociales. Universidad Nacional de La Plata. Buenos Aires: La Ley.

Picasso, S. (2013). La antijuricidad en el Proyecto de Código. Buenos Aires: La Ley.

Pothier, R. J. (1839). Tratado de las obligaciones. Primera parte. Barcelona: Sociedad de Amigos Colaboradores. Recuperado de https://es.scribd.com/document/28682194/TRATADO-DE-LAS-OBLIGACIONES-PDF [Fecha de consulta 04/01/19].

Wayar, E. C. (1990). Derecho Civil. Obligaciones. Buenos Aires: Depalma.

Fecha de recepción: 08-02-2019 Fecha de aceptación: 02-10-2019 
